\title{
A astúcia da matéria: Notas sobre a animação do inorgânico ${ }^{1}$
}

\section{Erick Felinto de Oliveira}

\section{Resumo}

Seria possível falar em uma tradição de "animação do inorgânico" no cinema experimental e nas intercessões entre cinema e arte? Em outras palavras, existiriam, na história do cinema, exemplos suficientes de vivificação de objetos inanimados - que, muitas vezes, se tornam mesmo o foco decisivo do olhar da câmera - de modo a podermos ali identificar um dado expressivo das estéticas modernas? Através da breve análise de alguns exemplos cinematográficos - mas também da esfera das artes plásticas e da literatura -, pretende-se operar com a hipótese de um progressivo declínio do tradicional ponto de vista antropocêntrico e do modelo de subjetividade humanista liberal a partir de pelo menos fins do século XIX. Declínio que as artes e 0 cinema irão representar exemplarmente por meio do protagonismo cada vez mais decisivo dos objetos.

\section{Palavras-Chave}

Objetos. Cinema Experimental. Barroco. Walter Benjamin. Jan Svankmajer.

Erick Felinto de Oliveira | erickfelinto@gmail.com Doutor em Literatura Comparada pela Universidade do Estado do Rio de Janeiro - UERJ, Brasil. Pesquisador do CNPq e professor do Programa de Pós-Graduação em Comunicação da UERJ.

\author{
A memória dos objetos é maior \\ que a memória humana \\ J. Svankmajer \\ La nature est toujours déjà baroque \\ Olivier Smolders
}

\section{Benjamin e Svankmajer: \\ a paixão barroca do inumano}

Em seu estudo sobre 0 drama de luto alemão

(Trauerspiel), Benjamin nota que a obsessão

do barroco com detalhes arquitetônicos e ruínas

expressa "a primazia do coisal (Primat des

Dinghaften) sobre o pessoal, do fragmentário

sobre 0 total" (BENJAMIN, 1991, I-1, p. 362)2.

No drama barroco, portanto, mesmo objetos

banais do cotidiano são infundidos com forças

que os lançam para além de si mesmos; eles são

(ou deveriam ser), de fato, caracterizados como

pessoas. É verdade que, por meio do mecanismo

da alegoria, as coisas se tornam entidades

alienígenas despidas de vida própria e colocadas

a serviço da causa alegórica, sempre conduzida

pela subjetividade do alegorista. Nesse império

delirante da subjetividade alegórica, recai-se,

por fim, no extremo de uma "embriaguez da aniquilação (Vernichtungsrauch), na qual tudo 
que é terreno colapsa em uma pilha de escombros" (ibid., p. 405). Entretanto, é nesse ponto que se processa uma reversão completa - de modo que da destruição radical emerge uma alegoria do despertar e da ressurreição.

Seria possível dizer, desse modo, que os objetos compõem parte importante da economia do drama barroco alemão, ainda que submetidos aos propósitos do alegorista. Para além disso, contudo, as coisas ocupam lugar central em vários outros momentos do pensamento benjaminiano, funcionando, frequentemente, como instrumentos de corrosão de nossas tradicionais atitudes antropocêntricas. Esse viés não antropocêntrico do pensamento de Benjamin pode ser identificado, por exemplo, na ideia de "História Natural" (Naturgeschichte), que, desempenhando papel central no estudo sobre o Trauerspiel, constitui um "chamado ético-teológico por um outro tipo de história, não mais puramente antropocêntrico ou ancorado apenas nas preocupações dos sujeitos humanos" (HANSSEN, 1998: p. 1). Ou seja, para Benjamin, assim como a noção de história não deveria ser aplicável unicamente ao mundo humano, também a noção de agência não poderia ser limitada à categoria de um atributo exclusivamente antrópico ${ }^{3}$. Mas as coisas não apenas agem, elas também falam. Em um pequeno ensaio cujas conexões com 0 livro do drama barroco foram assinaladas já por diversos analistas (por exemplo, MCCOLE, 1993; MENNINGHAUS, 1995), Benjamin, com efeito, estende o domínio da linguagem a todo o universo: "não há evento ou coisa, tanto na natureza animada, quanto na inanimada, que não tenha, de alguma maneira, participação na linguagem" (2011, p. 51) $)^{4}$ Trata-se do célebre e hermético ensaio "Sobre a linguagem em geral e sobre a linguagem do homem", no qual se propõe a curiosa tese de que todas as coisas se comunicam por meio de uma linguagem muda. É apenas porque as coisas se dirigem ao homem que este pode, efetivamente, nomeá-las. E "não se trata de antropomorfismo" (2011, p. 55), Benjamin preocupa-se em advertir, de forma algo misteriosa. Essa estranha noção de uma "língua em geral" (Sprache überhaupt) faz parte do vasto repertório de indícios que nos permitiria afirmar que a temática dos objetos abarca, de algum modo, todos os outros temas da obra benjaminiana, da estética à arte e à técnica (Kimmich, 2011, p. 55). É por essa razão que figuras como a do colecionador, sempre ocupado com as coisas e sua organização,

Este trabalho foi apresentado originalmente no XX Encontro da Socine, em outubro de 2016.

As referências ao original alemão remetem à edição em 14 volumes da Gesammelte Schriften (1991), organizada por Rolf Tiedemann e Hermann Schweppenhäuser, daqui por diante especificada com o número do volume e da parte. Por exemplo, Band I-1 (volume 1, parte 1).

Sobre a "agência dos objetos" em Benjamin, ver o artigo de NG, Julia (2011). Cf. ainda KIMMICH (2011) e BUSCH (2007).

Utilizamos aqui a excelente tradução "Sobre a Linguagem em Geral e sobre a Linguagem do Homem" (2011), de Susana Kampf Lages e Ernani Chaves. Ver bibliografia. 
merecem lugar de destaque nos escritos de Benjamin. Como lembra ainda Kimmich, citando outro texto do autor, os "colecionadores são os fisiognomistas do mundo coisal" (Physiognomiker der Dingwelt $)^{5}$. São eles que reorganizam 0 mundo dos objetos a partir de seus traços materiais e seus atributos sensoriais, muito mais do que de seus possíveis significados, praticando, assim, uma espécie de saudável "abstinência hermenêutica" (ibid., p. 63). E é por isso que, como afirma Benjamin no fragmentário PassagenWerk, "em cada colecionador [esconde-se] um alegorista, e em cada alegorista, um colecionador" (1991, V-1, p. 279).

Na qualidade, ele próprio, de colecionador e fisiognomista do mundo dos objetos, Benjamin, pode ser encarado como um dos mais destacados promotores de um processo de vivificação das entidades inanimadas que, paradoxalmente, se desencadeia na modernidade. Se os modernos tentaram, a todo custo, separar nitidamente os universos do orgânico e do inorgânico, do natural e do artificial, não é menos verdade que também foram eles que mais decididamente tematizaram 0 rompimento dessas classificações. Como descreve Kimmich, "o estabelecimento de fronteiras entre 0 animado e o inanimado (Lebendigem und Leblosem) e a simultânea violação dessas mesmas fronteiras parecem, pois, caracterizar a novidade do período moderno" (2011, p. 13). E é nas telas de cinema, segundo Kimmich, onde as coisas irão, antes de qualquer outro domínio da cultura, manifestar essa vivificação perturbadora e estranha. Partindo de uma análise do clássico de Béla Balázs, Der Sichtbare Mensch, a autora identifica o cinema como o horizonte por excelência no qual as coisas adquirem uma vida autêntica (e independente do homem). Tratase, assim, de uma redescoberta da "fisiognomia latente" (ibid., 2011, p. 87) dos objetos. Nesse contexto, o termo fisiognomia, anteriormente associado a Benjamin, adquire uma ressonância particularmente interessante. Como muitos outros conceitos do complexo teórico benjaminiano, a fisiognomia deriva do campo das pseudociências e das proposições esotéricas. Com raízes que se perdem na Antiguidade, ela consistia basicamente em uma técnica de leitura do caráter, da personalidade e das predisposições individuais a partir dos traços faciais.

Em sua erudita monografia sobre o tema, Richard Gray demonstrou que a obra de Johann Caspar Lavater, Physiognomische Fragmente, zur Beförderung der Menschenkenntniß und Menschenliebe (1775), provocou uma ampla revalorização da fisiognomia, transferindo-a do campo dos empreendimentos ocultistas e das mistificações para o das ciências empíricas legitimadas no âmbito do Iluminismo, e, particularmente, nas regiões da Europa de 
fala alemã (GRAY, 2004, p. xix). Desse modo, é possível falar em uma tradição fisiognômica no pensamento germânico, indo do próprio Lavater, e passando por autores como Goethe, Hegel e Schopenhauer, para chegar a Benjamin e muitos outros já no tardio alvorecer do século XX. Todavia, em Balázs (como em Benjamin), a fisiognomia adquire ainda a curiosa particularidade de referir-se igualmente às coisas:

Mas as coisas também têm rostos adoráveis e agradáveis. Quão frequentemente bem nos sentimos ao contemplá-las, como no tranquilizador sorriso de um amigo. E na maioria das vezes não sabemos, não notamos, de onde vem [esse rosto]. Não, não é da beleza decorativa, mas sim da fisionomia viva que todas as coisas possuem (von der lebendigen Physiognomie, die alle Dinge haben) $(2001,1924$, p. 59).

No domínio cultural de língua alemã, o tema conquista, de fato, tamanha fortuna que se torna também objeto de reflexão da crítica tradicionalista da tecnologia. Max Picard, que escreveu extensamente sobre a fisiognomia a partir de uma perspectiva filosófico-teológica, vê no cinema uma transmutação mecânica do rosto humano, na qual ele aparece sem presença real (Gegenwärtigkeit), sem uma essência autêntica (Dasein) $)^{6}$. A figura humana se converte, para ele, em um fantasma (Revenant), de modo que 0 rosto-cinema (Kinogesicht) revela-se "fantasmagórico sem fundamento" (1947, p. 147) - ou seja, sem possuir um passado ou presente. Esse rosto vazio e sem fundamento é o resultado da perda da relação humana com a eternidade, com a transcendência, que ainda era possível em um mundo tradicional e religioso, mas que se fragmenta no contexto da sociedade tecnológica. Não obstante sua perspectiva essencialmente humanista e teológica, Picard também se ocupa ocasionalmente dos objetos e sua potência ontológica. Em seu tratado sobre o silêncio (Die Welt des Schweigens, 1947), afirma ser precisamente este 0 responsável por devolver as coisas ao mundo do ser integral (ganzen Daseins), reparando o dano que a exploração dos determinantes utilitários lhes inflige. É apenas quando são envelopadas no silêncio - longe, portanto, das etiquetas que a dimensão pragmática da existência lhes atribui - que as coisas recobram sua autêntica densidade ontológica (1947, p.11). Mas importa lembrar que se trata de uma "inutilidade sagrada" (heilige Nutzlosigkeit) - na qual o homem deve necessariamente ser um ator fundamental.

Significativamente diferentes são as perspectivas de Benjamin e Balázs, em cujos textos as coisas mudas desenvolveram uma "linguagem dos olhos, uma gramática do olhar" (Kimmich, 2011, p. 88) - e onde encontramos uma alternativa às abordagens antropocêntricas. No cinema se encenam os debates sobre a crise da linguagem, a natureza da realidade e os novos projetos de subjetividade que tanto marcaram a experiência 
moderna. Mais que isso, a guerra que 0 cinema empreende (através de figuras como Chaplin, por exemplo) contra a civilização instrumental moderna termina com a vitória das crianças, dos loucos e dos selvagens, que "encaram as coisas de tal modo que elas recebem uma 'alma'” (Kimmich, 2011, p. 92).

Isso nos permitiria jogar com a ideia do cinema como "mágica moderna", exatamente como faz Rachel Moore em seu estudo sobre o pensamento primitivo nas teorias do cinema. De acordo com Moore, os primeiros estudos sobre 0 cinema mergulharam em noções antropológicas tradicionais, como o animismo, o ritual e o sagrado, de modo a explicar o poder da tecnologia diante das plateias modernas. Esse fascínio com 0 primitivo - que, de alguma maneira, nos remete também ao conceito marxista do fetichismo da mercadoria - demonstra que 0 impulso tecnológico de forma alguma eliminou a dimensão irracional da existência. 0 caráter mágico do cinema acabou por criar uma "fantasmagoria de objetos vivos e sujeitos mudos" (MOORE, 2000, p. 4). Trata-se de colocar a nu a experiência cinematográfica em sua dimensão de "segunda natureza", por meio do retorno a um olhar no qual os processos tecnológicos ainda não haviam sido, de fato, "naturalizados" ". Ao debruçar-se sobre os escritos de Jean Epstein, Eisenstein e Benjamin, Moore discute a "vida secreta dos objetos" no contexto do cinema a partir de uma dupla perspectiva: "como mercadoria e como fetiche religioso" (2000, p. 76). No clássico de Robert Bresson, L'Argent (1983), Moore encontra, por exemplo, uma concepção de objeto despida de toda transcendência possível e que se baseia, antes, na sua pura materialidade, uma espécie de adoração das coisas por si mesmas. De fato, nas obras de Bresson ou de cineastas como Douglas Sirk e Kenneth Anger, deparamo-nos com a substância das coisas, mas uma substância que "aparenta desejar estar lá" (MOORE, 2000, p. 83). Essa potência do material no cinema é destacada também por Kracauer em sua Theory of Film (1960). Para ele, uma das marcas da modernidade é seu caráter abstrato, tecido sob o império da ciência e da tecnologia. Vivemos, portanto, sob a constante sensação de que as coisas se afastam de nós, perdemos contato com a experiência de sua materialidade. Nesse contexto, escreve Kracauer, "o cinema pode ser definido como um médium particularmente equipado para promover a redenção da realidade física" (1960, p. 300), oferecendo um modo de ver que permite enxergar aquilo que 0 olho humano não consegue. Há que se notar, aqui, o interessante paradoxo: ciência e tecnologia produzem a abstração que nos afasta do mundo, mas é essa mesma tecnologia, configurada no aparato cinematográfico, que nos pode devolvê-lo ${ }^{8}$. 
Poucos realizadores exploraram essa potência material das coisas como o tcheco Jan Svakmajer. Em seu Spiel mit Steinen ("Jogo com Pedras", 1965), por exemplo, tanto a trilha sonora (o tiquetaque do relógio e as tonalidades mecânicas da caixa de música) quanto as imagens cooperam para produzir um efeito de palpabilidade, de densidade das coisas (pedras, paredes, relógio), quase como se pudéssemos sentir suas superfícies rugosas passando por nossas mãos ${ }^{9}$. Mais que isso, porém, Spiel mit Steinen parece transformar também o próprio tempo em um "objeto" palpável. A matéria pétrea, que registra, em seu interior e exterior, a passagem do tempo, encarnaria os ritmos da temporalidade, em seus jogos infindáveis entre repetição e diferença. Nos planos iniciais das rachaduras e teias de aranha nas paredes brancas, assim como, em seguida, na dança das pedras, com seus movimentos coordenados pela música mecânica (ora graciosos e lentos, ora rápidos e abruptos), a passagem do tempo ganha uma dimensão sensível. Em cada sequência - que se repete diversas vezes com variações - as pedras saem, como uma espécie de matéria 'líquida-sólida', da torneira estranhamente acoplada ao relógio. Na sequência final, as pedras já não são mais recebidas pelo balde que antes as acolhia - e no qual agora aparece um enorme rombo. Elas simplesmente se acumulam no chão em uma pilha, enquanto o pêndulo do relógio continua a mover-se. Se o tempo se inscreve nos objetos com os signos da decomposição e das ruínas, ele mesmo segue incessantemente em seu percurso sem corrosão. Em Spiel mit Steinen, 0 tempo torna-se uma realidade tátil. É tentador, aqui, evocar o conhecido fragmento heraclítico: "0 tempo é uma criança, criando, jogando o jogo de pedras; vigência da criança" $(1991, \text { p. } 73)^{10}$.

Uma série de convergências interessantes liga a obra de Svankmajer aos temas de Benjamin. Em ambos, encontramos, por exemplo, o mesmo fascínio com o Barroco e o Surrealismo, com os gabinetes de curiosidades (Wunderkammer) e o tema da destruição. Na entrevista concedida a Peter Hames, Svankmajer ilustra essa proximidade ao evocar uma figura tipicamente benjaminiana, a do colecionador:

Eu sou um colecionador, mas sou assistemático. Eu coleciono impressões dos sentimentos dispersos que encontro em certos objetos, seja

Segundo Roger Cardinal, Svankmajer nos apresenta os objetos como se nos solicitasse não apenas que os "lêssemos como inscrições, mas também [...] deixássemos nossos olhos roçar através deles, imaginando como iríamos senti-los (como nós nos sentiríamos) se pudéssemos tocá-los" (2008, p. 74).

10 A tradução do fragmento é incerta. A versão apresentada aqui é de Emmanuel Carneiro Leão e Sérgio Wrublewski (VVAA,

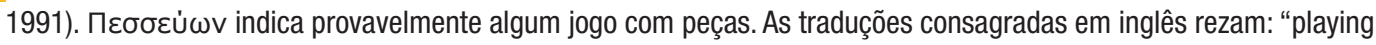
draughts" (jogando damas) ou "moving pieces in a game" (movendo peça em um jogo) - por exemplo, em (KAHN, 1979, p. 71). Todavia, é bem possível que suas peças fossem pequenas pedras, e, na tradição alemã, a palavra "pedra" (Stein) é de uso recorrente, como na solução de Diels: "Die Lebenszeit ist ein Knabe, der spielt, hin und her die Brettsteine setzt" (1960, p. 162). Talvez por influência desta passagem de 0 Nascimento da Tragédia: "[...] wie wenn von Heraklit dem Dunklen die weltbildende Kraft einem Kinde verglichen wird, das spielend Steine hin und her setzt [...] (NIETZSCHE, 1979, p. 108). Trad.: "[...] como quando Heráclito, o obscuro, compara a força constituinte do mundo a uma criança, que assenta pedras aqui e ali..." 
esse objeto sem valor ou uma obra de arte, um produto da natureza ou um achado fortuito. Esses objetos não são artefatos mortos para mim. Eu amorosamente Ihes dou papéis de destaque em meus filmes (2009, p. 116).

Em Benjamin, o colecionador, assim como 0 fisiognomista, distribui as coisas do mundo a partir de uma paixão situada entre a ordem e a desordem, sempre flertando com 0 caos. Ele lê a vida interior do capital a partir das mercadorias como signos da experiência coletiva, salvando os objetos de sua dispersão e exibindo as afinidades nem sempre evidentes que entretêm uns com os outros. Como em Max Picard, não se trata, aqui, de agarrar-se à dimensão utilitária ou funcional das coisas, mas antes de "encerrar itens individuais em um círculo mágico (Bannkreis) no qual estão congelados, enquanto que a última excitação, o frisson da aquisição, passa sobre eles" (BENJAMIN, 1991, IV-1, p. 389). Esse é o "mais profundo encantamento do colecionador" (die tiefste Bezauberung des Sammlers), afirma Benjamin, lançando mão do vocabulário mágicoesotérico com o qual frequentemente vestia seu pensamento. Como os fisiognomistas de outrora, o colecionador é um intérprete do destino

(Schicksalsdeuter), mas não dos rostos humanos e sim das coisas. Ele renova a vida dos objetos, conectando sua história passada ao seu futuro potencial. Desse modo, poder-se-ia dizer que 0 colecionador reorganiza os objetos no espaço $e$ no tempo, conferindo-lhes sentidos inteiramente diversos dos que possuíam em seus contextos originais. Como explica Tyrus Miller em seu ensaio sobre o Passagen-Werk, ali Benjamin formula argumentos estruturados no pano de fundo da filosofia de Bergson. Seu raciocínio aproxima 0 colecionador do sonhador (e aqui temos também uma defesa da atitude surrealista), já que ambos

\begin{abstract}
estabelecem uma reciprocidade dinâmica entre a objetividade e o tempo que é diferente da perspectiva estática na qual os objetos nos aparecem na vida cotidiana. A objetividade cotidiana, segundo Bergson, depende do mascaramento dos diferenciais do tempo sob o disfarce de objetos estáveis, dados, com suas formas externas, quantitativas, especializadas. 0s objetos do colecionador e do sonhador, em contraste, são apenas os elementos componentes de complexas imagens temporais: memórias, representações históricas ou genealógicas etc. Na vida cotidiana, os 'objetos' têm precedência sobre as imagens do tempo. No sonhar e no colecionar, por outro lado, as qualidades, valores e significados dos objetos derivam de seu lugar em uma tentativa, sempre em evolução e sem término determinado, de tornar o tempo visível (ou tangível) (MILLER, 2006, p. 249).
\end{abstract}

Importa assinalar que a paixão assistemática ou caótica do colecionador foi 0 impulso fundamental para a criação dos gabinetes de curiosidade barrocos (Wunderkammer), que tanto impressionaram Svankmajer. Mas as proximidades entre 0 filósofo e 0 artista não cessam por aqui. Em 1967, Svankmajer produziu o curta Historia Naturae, no qual diferentes ordens animais são mostradas em imagens acompanhadas por variados estilos musicais, sempre intercaladas com um plano-detalhe de uma boca humana devorando um pedaço de carne. Em Benjamin, e especialmente no estudo sobre o drama barroco, o tema da "História Natural" 
(Naturgeschichte) constitui elemento central estruturador do pensamento. Ao lançar mão desse termo, Benjamin visava desencadear a particular configuração histórica do Barroco, sugerindo uma noção muito singular de história, não mais ancorada em pressupostos antropocêntricos (HANSSEN, 1998). Daí o fascínio do filósofo com as entidades não humanas, como os anjos, os animais ou mesmo as pedras. 0 domínio da história natural é não apenas aquele da morte e da decomposição - tradicionais símbolos barrocos, como já vimos, e fortemente presentes em Svankmajer -, mas também sítio de uma possível ressurreição (e de uma animação do inorgânico). Em diversos de seus ensaios, Benjamin se engajou com essas variantes possíveis do Unmensch (o inumano), com "aquilo que tradicionalmente se situa fora das fronteiras do sujeito humano" (HANSSEN, 1998, p. 105) tanto em um sentido positivo, que se aproxima do que hoje denominamos como "animal studies", quanto em um diapasão negativo, indicador dos limites violentos e destrutivos do humano. Na obra de Svankmajer, o plano-detalhe da boca humana devorando o que se supõe ser carne animal constitui, paradoxalmente, 0 elemento mais inumano no conjunto total das imagens. Essa figuração destrutiva é o contraponto de uma apresentação da animalidade que lança mão (de modo irônico) das categorias taxonômicas com as quais tentamos ordenar a natureza, mas cuja racionalidade é, ao mesmo tempo, contestada pela rápida sucessão de rostos, esqueletos e imaginativos desenhos de animais. No curta de
Svankmajer, os animais, mudos como as coisas, parecem expressar-se. E a história que contam é de sua apreensão indevida nas malhas da racionalidade ordenadora dos homens.

\section{Olivier Smolders: A noite negra das coisas}

Os filosofemas de Benjamin e os trabalhos de Svankmajer poderiam ser incluídos em uma longa tradição de animação do inorgânico assentada, como mostra Spyros Papapetros, em curiosas discussões sobre animismo e espiritismo centrais aos campos da arte e da arquitetura. A partir do século XVIII, porém, as tradicionais metáforas corporais se convertem em sintomas patológicos interiores, "afligindo o organismo de estátuas, prédios e metrópoles modernas" (2012, p. vii). Ameaçada pelo mundo exterior, cada vez mais complexo e dominado por uma multidão de aparatos mecânicos e elétricos, a subjetividade moderna desloca seu ego para os objetos inanimados em um desejo de domínio irrestrito. Ao fazê-lo, porém, acaba por produzir um resultado contrário ao esperado, investindo objetos com poderes psíquicos e, gradualmente, enfraquecendo sua própria subjetividade. Segundo Papapetros,

a invenção da teoria da empatia e o reavivamento do antropomorfismo, assim como a fisiognomia dos objetos retrata a tentativa fracassada da estética finissecular de subjetificar (e assim neutralizar) 0 poder radical dos artefatos tanto nas sociedades arcaicas como nas modernas (ibid., p. ix). 
No campo das artes plásticas, muito para além das tradicionais "naturezas mortas", os objetos irão ocupar posição fundamental. E é, provavelmente, no domínio do maquinismo que eles sairão do fundo do mundo para se tornarem agentes sociais e forças culturais determinantes. 0 futurismo, por exemplo, cantará os louvores da máquina e da velocidade na sociedade industrial. Dessa forma, o caráter anti-humanista das vanguardas se manifesta claramente no parti pris das máquinas e da cidade contra a ideologia da natureza. No início do século XX, a presença cotidiana dos aparatos tecnológicos torna o maquinismo uma espécie de divindade ou duplo do homem. A imagem da máquina, tal como a interpretam os textos de Francis Picabia, por exemplo, constitui um tipo de "ex-voto ou objeto de exorcismo" (LE B0T, 1973, p. 159). Se em um artista como Picabia elas aparecem de modo explícito, em outros elas funcionam como modelos operatórios para a cultura e o comportamento. Dessa maneira, "à mitologia do homem se substitui, de início, um mito triunfalista da máquina" (ibid., p. 193194) - Léger, por exemplo, almejará que suas obras rivalizem em beleza com o objeto técnico; Apollinaire registrará a crise do sujeito; John Heartfield, cujas fotomontagens eram admiradas por Benjamin, irá mesclá-las à natureza e às figuras humanas. Máquinas, objetos, autômatos, seres mecânicos: suas representações irão obcecar a arte e a literatura modernas, em muitas instâncias contribuindo, ao menos de forma acessória ou secundária, para a criação daquela espécie de ambiência que Freud, evocando
Jentsch, define como "estranha" (Unheimliche) (Cf. FREUD, 1976). E na historiografia da arte, talvez os temas da empatia e da "animação do inorgânico" inclusive antecipem a noção freudiana, conforme sugere Papapetros em sua análise do clássico de Wilhelm Worringer, Abstraktion und Einfühlung (Cf. PAPAPETROS, 2012, p. 133).

No cinema, essa presença atuante das coisas e dos aparatos (inclusive dos próprios aparatos cinematográficos) irá se manifestar desde seus primórdios. Em seu estudo clássico sobre a história do cinema experimental, Jean Mitry atribui a Griffith, em The Avenging Conscience (1913), o que seria a primeira instância de um uso expressivo dos objetos no cinema. Nos planos-detalhe de um lápis, de um relógio e de um pêndulo de relógio, manifesta-se

o primeiro momento em que a montagem, pelo poder simbólico dos objetos, pela cadência mortal do ritmo, traduzia literalmente as pulsações de um coração angustiado e os remorsos de uma consciência culpada (1974, p. 20).

A teoria do cinema acompanhará de perto essa vida das coisas na tela - e também desde bem cedo. Se é verdade que as primeiras teorias frequentemente apelavam ao primitivo e ao mágico - aí incluída a noção animista do fetiche -, também é fato que os objetos encontrarão acolhida expressiva em autores como Delluc, Balázs e Epstein. Fundadas na ideia de que as particularidades técnicas do cinema lhe permitiam revelar um mundo invisível 
aos limitados olhos humanos, essas teorias continuamente destacaram a expressividade das coisas no universo cinematográfico. De acordo com Francesco Casetti, pode-se extrair três consequências importantes dessa perspectiva focada nos objetos: 1. ao revelar a presença das coisas na tela, o cinema as carrega de novos significados, afastados da costumeira esfera funcional e utilitária; 2. ao apresentá-los para além de suas meras funções, 0 cinema nos permite enxergá-los em sua pura "coisidade" (ou materialidade) e 3. com sua capacidade de apresentar 0 mundo em devir, 0 cinema nos mostra o movimento nas coisas. Dessa forma, emergem três diferentes sentidos dos objetos, como instrumentos (ou seja, portadores de novos significados), coisas e eventos (CASETTI, 2015, p. 26). Se tanto as teorias como o próprio cinema se ocuparam seguidamente de sua dimensão coisal, talvez seja possível inclusive empreender novas arqueologias do cinema que não partam do tradicional paradigma fotográfico, mas de outros aspectos e problemáticas tecnológicas do meio ou mesmo de objetos externos, como o carrossel, segundo propõe, imaginativamente, Thomas Elsaesser (2015, p. 45). Exemplo interessante de uma empreitada próxima dessa sugestão é o trabalho de Stefan Andriopoluos, Possessed (2008), que, ao se debruçar sobre o cinema expressionista, ali encontra uma verdadeira obsessão com os tropos do esvaziamento da subjetividade do espectador (que, pois, se "coisifica") e da corporação como organismo social dotado de agência. Na conjunção entre os temas da hipnose e da entidade corporativa, os filmes do Dr. Mabuse, por exemplo, revelam um pânico cultural centrado no perigo da fragmentação da interioridade e da identidade. Como explica Andriopoulos,

No romance de Norbert Jacques e no filme de Lang, a figura do Dr. Mabuse funciona como a personificação ou materialização (embodiment) de um organismo corporativo intangível, que elude a percepção direta e manipula a bolsa de valores (2008, p. 124).

É apenas mais tarde, todavia, que os objetos irão tornar-se atores centrais no palco da cultura. De fato, os últimos 20 anos testemunharam não somente um aumento significativo da preocupação com o declínio das visões de mundo antropocêntricas, senão que as coisas passaram a ocupar posições fulcrais da cena epistemológica contemporânea. Não é casual 0 fato desse prestígio das coisas ser acompanhado por uma renovação do interesse pelo Barroco ou pela repetição exaustiva da ideia de um espírito neobarroco na cultura contemporânea (Cf.

CALABRESE, 1999). Tudo isso se dá precisamente no contexto de uma decidida fascinação das humanidades com os objetos (em especial, os objetos tecnológicos) e pela materialidade do mundo; uma cena teórica marcada pela ascensão de propostas filosóficas como a da "ontologia dirigida aos objetos", dos "novos materialismos" e das "materialidades da comunicação"

(Cf. HARMAN, 2011; COLE \& FROST, 2010; GUMBRECHT \& PFEIFFER, 1994), bem como por reconfigurações radicais das ciências sociais, 
como a operada por Bruno Latour com seu "parlamento das coisas" (Cf. LATOUR, 2000). No campo específico do audiovisual, William Brown chega, inclusive, a identificar um caráter "não antropocêntrico" do cinema digital, no qual "ambientes assumem um papel proeminente nos filmes, incluindo filmes mainstream" (2015, p. 2).

Se é possível, portanto, falar em um "retorno das coisas" (Wiederkehr der Dinge) e de uma despedida da metafísica do sujeito, como fazem Friedrich Balke, Maria Muhle e Antonio von Schöning em recente coletânea de ensaios, é no contexto de uma perspectiva de pesquisa cultural e midiática que conecta elementos heterogêneos em uma moldura sempre precária e flexível - na qual movimentos de reterritorialização encontram-se em atividade constante (2011, p. 15). 0 cinema acompanhou, naturalmente, essa ascensão dos objetos, e realizadores como David Lynch, Michel Gondry e Michael Haneke ${ }^{11}$ estão entre os exemplos mais destacados do atual interesse cinematográfico pelo mundo das coisas. Nas linhas que se seguem, quero concentrar-me em um artista menos conhecido, mas que talvez encarne como poucos as conexões entre barroco, o protagonismo dos objetos e a corrosão do antropocentrismo. Trata-se do belga Olivier Smolders, nascido em 1956, no Congo, e autor de diversos filmes experimentais, além do longa Nuit Noire.
Carregados de uma imagética barroca e de uma poesia que flerta com o grotesco, os trabalhos de Olivier Smolders buscam nos gabinetes de curiosidade, nos museus de história natural e no animismo algumas de suas fontes centrais de inspiração. Em Petite Anatomie de L'Image (2009), por exemplo, uma trilha sonora espectral funciona como base para uma sucessão de imagens de um museu anatômico. 0 espelhamento das realistas reproduções de corpos e membros, músculos e órgãos produz um efeito que, se, por um lado, evoca a anamorfose, por outro engendra um universo ainda mais bizarro, em que 0 humano se torna repentinamente estranho, monstruoso, deslocado. As imagens são de corpos-objeto, estátuas de cera produzidas por artistas florentinos do século XVIII. Na montagem e na manipulação das imagens, o filme replica as incisões, cortes e fragmentações dos corpos apresentadas nas estátuas. A parte final do filme, porém, é dominada pela evocação de um instrumento ótico, o caleidoscópio, que multiplica a tal ponto as partes dos corpos bem como as caixas de vidro nas quais muitas das estátuas se encontram encerradas - que qualquer ponto de referência possível é abolido. 0 corpo humano se torna ali local de vertigem perturbadora, sempre assombrado pelo espectro barroco da morte e da degradação, e deixandonos com uma imagem coisal do humano, na qualidade de objeto de estudo a ser dissecado pelo olhar objetivo dos anatomistas. 
Em Voyage autour de ma Chambre (2008), que se propõe como uma espécie de passeio pendular entre o escritório do realizador e cenas de diferentes partes do mundo registradas como em um travelogue, os objetos adquirem uma posição ainda mais central. Objetos que constituem o mundo pessoal do autor e, portanto, parecem dele receber uma espécie de vida vicária. Smolders nos apresenta uma parcela de sua intimidade, expressa nas coisas que refletem seus gostos, particularmente moldados pela influência do Barroco, do Surrealismo e do fascínio com a história natural. Em uma alternância entre planos abertos e fechados, 0 filme mostra uma enciclopédia anatômica na mesa do artista, os computadores com imagens de seus filmes, os insetos e as pedras que coleciona apaixonadamente, as fotografias da infância. Com uma narração em off que, combinada às imagens, faz lembrar a lógica de Sans Soleil (1983), de Chris Marker, Voyage autour de ma Chambre demonstra, como explica 0 autor nessa mesma narrativa, que, "para viajar para longe e por longo tempo, basta observar um pequenino fragmento do mundo (un tout petit morceau du monde): uma pedra, um inseto, uma concha". A viagem tem início, portanto, no espaço da intimidade, nas pequenas coisas que constituem o universo particular do autor. Entre esses objetos, destacamse as pedras, com suas texturas e suas sedutoras materialidades multiformes - objetos que possivelmente constituem, conforme a narrativa, "esse pequeno poema que a natureza elabora com uma mescla sábia de rigor e fantasia".

Entretanto, é somente em seu único longa, Nuit Noire (2004), que Smolders concede a essa poética dos objetos a sua expressão mais desenvolvida. Como afirma uma resenha sobre 0 filme na internet, Nuit Noire possui a estranha "habilidade de dotar objetos, como um colar, de um poder análogo ao do vodu"12. Mesclando imagens poéticas com uma ambiência sombria, estranha e aterradora, o longa de Smolders constrói uma intrigante narrativa surrealista, passada em um mundo onde a noite parece ser eterna (os dias duram apenas breves 15 segundos) e os sonhos têm papel de destaque. De fato, já na primeira cena do filme, o espectador é apresentado ao universo onírico de 0scar, o protagonista que trabalha diligentemente como entomologista em um museu de ciências naturais. Todavia, só se percebe tratar-se de um sonho quando, na sequência seguinte, Oscar aparece com um estranho aparato introduzido na orelha - objeto que permite a um psiquiatra sondar o imaginário mental de seu paciente. Essas imagens iniciais já oferecem pistas importantes para a lógica narrativa da obra (se é que aqui podemos, de fato, falar em "lógica"). Oscar tem repetidamente sonhos violentos sobre sua irmã, aparentemente morta por um animal selvagem - ainda que 
seu terapeuta afirme que tudo se trata de uma invenção imaginativa e que ele "provavelmente sequer teria uma irmã”. A questão psicanalítica da culpa e do retorno do reprimido, assim como 0 tema da memória, real ou inventada, emergem de modo claro, portanto, desde o início do filme.

Oscar possui uma rotina aparentemente tranquila, ocupando-se, tanto em casa como no museu, de suas coleções de insetos. Isto é, pelo menos até 0 dia em que chega em casa e encontra uma mulher africana deitada em sua cama. Ele tenta expulsála, mas a mulher parece estar doente, e, desse modo, acaba tornando-se uma presença incômoda, mas tolerada. Certa noite, Oliver acorda nu na cama ao lado da visitante indesejada. A mulher engravida, mas, ainda doente e atormentada por visões de Marie Neige, a misteriosa irmã de Oliver, se suicida com um tiro na têmpora. Entretanto, Oliver submete o cadáver a um estranho processo de embalsamamento, procedimento que irá convertê-lo em um gigantesco casulo, do qual nascerá o que parece ser uma versão adulta de sua irmã desaparecida. Oliver faz amor com Marie Neige, e desse gesto de rebeldia incestuosa nasce, pela primeira vez, um dia normal de sol no mundo da noite quase eterna de Nuit Noire. Porém, a luz é perigosa, como diz um dos personagens com quem Oliver conversa. "A luz estragou tudo", afirma ele. "Não há mais imagens, não há filme, não existe mais cinema!" - conclui ao despedaçar um rolo de película. No final da história, o longo eclipse retorna, e Oliver vaga pelas espectrais ruas da cidade escura, deparando-se no caminho com um elefante. Ao retornar para casa, vê que sua coleção de insetos misteriosamente adquiriu vida, e borboletas voam soltas pela residência. Oliver coloca o revólver na boca de Marie Neige, e o filme termina então com uma cena onírica primal da infância, na qual o protagonista tenta proteger sua irmã, agora negra, do animal que ataca: uma onça, logo substituída pela imagem de um homem africano sob a pele do animal.

Em seu fascínio barroco com objetos e coleções, e especialmente evocativo dos gabinetes de curiosidades $^{13}$, Nuit Noire é um filme obcecado com o poder simbólico das coisas. 0 objeto que parece destacar-se nesse contexto, além do colar que encerra um tufo de cabelos de Marie Neige, é a curiosa caixa ou relicário no qual Oliver guarda recordações de seu passado: fotografias, rolos de filme, brinquedos, uma mão de cera, o próprio colar. É dentro da caixa, em uma pequena tela, que Oliver assiste repetidas vezes a um filme em preto e branco, sempre incompleto, com cenas de sua infância. Se é legítimo acreditar nos relatos compilados por Smolders em seu livro La part de l'ombre - e que teriam servido como inspiração e esboço mental para o filme -, a ideia do gabinete 
de memórias foi dada por um amigo, dono de um relicário contendo as lembranças materiais de um amor ilícito do passado - "um conjunto que transpirava devoção religiosa" (2005, p. 155).

De toda maneira, 0 realizador sempre sofreu da paixão do colecionador. Como explica Robin Pineda em sua dissertação sobre Smolders, 0 artista possui uma vasta coleção de caixas de objetos (shadow boxes), a maioria feita por ele próprio, e seu longa Nuit Noire "nasceu de seu desejo de filmar esses objetos" (2014, p. 33). Com Benjamin, já havíamos aprendido que colecionar envolve sempre as dimensões da memória e do esquecimento. Pineda também aponta isso, sugerindo, precisamente a partir de Benjamin e da obra de Smolders, que o gesto do colecionador constitui uma experiência liminal ${ }^{14}$, uma erupção caótica que pode desmontar a própria identidade do colecionador. De fato,

na maior parte da obra de Smolders existe um sentido material imanente inscrito no enquadramento. De certo modo, a objetidade (objectness) é imanente ao campo visual. Tão logo o 'objeto' está no enquadramento e the é dada sua devida duração, ele está livre para tornar-se uma outra coisa. Esse fascínio com o 'objeto' já é evidente em L'amateur através dos vários objetos reais que povoam sua mise-en-scène: móveis, uma caixa de música, um espelho, um fonógrafo, uma marionete, uma faca, etc (2014, p. 28-29).

Como muitos filmes de Svankmajer e também do próprio Smolders, Nuit Noire é uma sinfonia barroca das coisas, na qual oposições como vida e morte, branco e negro, dia e noite, luz e sombra, vigília e sonho funcionam como polos estruturantes. Todo objeto é deslocado de sua dimensão utilitária e transformado em alegoria. Em Nuit Noire, o Surrealismo, que Benjamin definira como uma "iluminação profana", é também um "mundo de coisas" (Dingwelt), em que uma comunhão entre sujeitos, corpos e objetos permite a eclosão de tensões revolucionárias, manifestadas em imagens de sonho (BENJAMIN, 1991, II-1, p. 310). Desse modo, seria possível dizer que o filme de Smolders é, além de tudo mais, uma crítica do colonialismo e dos processos de exotização da alteridade. A África imaginária, o negro exótico são alegorias do outro que nos seduz e aterroriza ao mesmo tempo. Um outro que pode encarnar em diversas figuras: na mulher, no animal, nos monstros, nas coisas. Nesse sentido, Nuit Noire dialoga com outro filme que tem também objetos como figuras principais. Trata-se de Les Statues Meurent Aussi (1953), de Chris Marker, Alain Resnais e Ghislain Cloquet, no qual as estátuas e máscaras africanas indicam, segundo a narrativa em off do documentário, que "todo objeto é sagrado, pois toda criação é sagrada", e que a morte é um "país onde se vai perdendo a memória". Se 0 sonho é uma forma de recuperar a memória que foi esquecida, reprimida ou falseada, o cinema é 0 vasto sonho de uma humanidade empenhada no constante e conveniente olvido de sua condição animal e coisal. 


\section{Conclusão: A astúcia da matéria}

Para Spyros Papapetros, os sujeitos modernos aprenderam a dominar seus medos e a controlar a plasticidade de seus desejos. A afirmativa talvez seja um pouco ousada, mas há que se concordar com 0 autor no que tange ao nosso engajamento contemporâneo em uma "comunicação transespécie com outras formas de matéria, seja vegetal, animal ou mineral - tudo que possa facilitar sua fuga do que chamamos de humano" (2012, p. 317). De fato, uma marca central de nossa era se encontra nesse interesse pelo inumano, por uma conversação com outras espécies, como há tempos já sugerira Vilém Flusser, em textos como Seres de Outro Mundo ${ }^{15}$ ou Vampyroteuthis Infernalis. Neste último trabalho, Flusser provavelmente parafraseia o filósofo Friedrich Vischer, ao falar em uma "astúcia da matéria" (Tücke der Materie), que expressa a resistência das coisas às nossas tentativas de dominá-las. Pois a arte, para 0 pensador tcheco, consiste em um processo de inscrição da memória em suportes materiais. As coisas se obstinam em sua resistência aos nossos esforços de informá-las, por isso são "objetos" - em alemão: Gegenstand, o que poderia ser traduzido como um ficar ou colocar-se (stehen) contra (gegen). Essa resistência nos provoca, como um chamado especificamente dirigido ao homem. Aqui não é difícil escutar um eco da ideia benjaminiana da convocação que as coisas dirigem ao homem para nomeá-las. Quem falha em atender a esse chamado, leva uma existência inautêntica (falsches Dasein). Pois o encontro desses dois polos modifica essencialmente tanto 0 sujeito como 0 objeto.

Se no futuro talvez possamos imaginar uma arte imaterial, prescindindo dos objetos e atingindo nossos cérebros de forma direta, hoje ainda dependemos deles. 0 aparato cinematográfico é, possivelmente, um dos mais significativos "objetos" nos quais buscamos preservar e transmitir nossa memória. Mas Flusser sugere que já estaríamos, aos poucos, realizando essa transição para uma arte "vampiromórfica"16 - e isso, paradoxal e precisamente, graças às tecnologias eletrônicas que povoam nossos ambientes culturais. Afinal, "construímos cromatóforos (televisão, vídeo, monitores de computador transmissores de imagens sintéticas), com cujo auxílio o emissor enganosamente alicia 0 receptor" (FLUSSER, 2002, p. 65). A arte e 0 cinema compõem, portanto, parte fundamental da história do embate do homem com o mundo, com os objetos, com a volatilidade da memória. Dessa maneira, a própria distinção entre sujeito e objeto revela-se algo ilusória. Viveremos não apenas na memória dos outros, como sugeriu Flusser, mas

15 Texto inédito preservado no Arquivo Flusser, de Berlim. 0 título original é "Wesen aus einer anderen Welt". Para uma tradução, consultar a obra de FELINTO e SANTAELLA (2012).

16 Ou seja, imaterial. Cf. (Flusser, 2002). 
também na memória das coisas. Uma memória menos frágil, cuja fisiognomia está para sempre plasmada nas imagens, belas e aterradoras, desse aparato fantasmagórico que é o cinema.

\section{Referências}

ANDRIOPOULOS, Stefan. Possessed: Hypnotic Crimes, Corporate Fiction, and the Invention of Cinema.

Chicago: The University of Chicago Press, 2008.

BALÁZS, Béla. Der sichtbare Mensch, oder die Kultur des Films. Frankfurt am Main: Suhrkamp, 2001.

BALKE, Friedrich; MUHLE, Maria; von Schöning Antonia (orgs.). Die Wiederkehr der Dinge. Berlin: Kadmos, 2011.

BENJAMIN, Walter. Gesammelte Schriften (vols. I-VII). Frankfurt am Main: Suhrkamp, 1991.

Escritos sobre Mito e Linguagem. São

Paulo: Livraria Duas Cidades, 2011.

BROWN, William. Supercinema: Film-Philosophy for the Digital Age. New York: Berghahn, 2015.

BUSCH, Kathrin. Dingsprache und Sprachmagie:

Zur Idee latenter Wirksamkeit bei Walter Benjamin. Transversal, v. 01, 2007. Disponível em < http://eipcp. net/transversal/0107/busch/de> . Acesso em: 3 set. 2016.

CALABRESE, Omar. A Idade Neobarroca. Lisboa: Edições 70, 1999.

CARDINAL, Roger. Thinking Through Things:

The Presence of Objects in the Early Films of Jan Svankmajer. In: HAMES, Peter (ed.). The Cinema of Jan Svankmajer: Dark Alchemy. London: Wallflower Press, 2008.

CASETTI, Francesco. Objects on the Screen: Tools, Things, Events. In: PANTENBURG, Volker (ed.). Cinematographic 0bjects: Things and Operations. Berlin: August Verlag, 2015.
COLE, Diana \& FROST, Samantha. New Materialisms: Ontology, Agency, and Politics. Durham: Duke University Press. 2010.

DIELS, Hermann. Die Fragmente der Vorsokratiker (Band I). Berlin: Weidmannsche, 1960.

ELSAESSER, Thomas. Round and Round:

Horses, Carousels, and the Meta-Cinema of Mechanical Motion. In: PANTENBURG, Volker (ed.). Cinematographic Objects: Things and Operations. Berlin: August Verlag, 2015.

FELINTO, Erick. Vampyroteuthis: a Segunda Natureza do Cinema - A 'Matéria' do Filme e o Corpo do Espectador. Flusser Studies n. 10. Lugano: Università della Svizzera Italiana (Nov. 2010). Disponível online em < http://www.flusserstudies.net/sites/www. flusserstudies.net/files/media/attachments/felintovampyroteuthis.pdf $>$ . A Coisa que me Olha: os Objetos Sinistros de Michael Haneke. In: CAPISTRANO, Tadeu (org.). A Imagem e o Incômodo: 0 Cinema de Michael Haneke. Rio de Janeiro: Caixa Cultural, 2011. \& SANTAELLA, Lucia. 0 Explorador de Abismos: Vilém Flusser e o Pós-Humanismo. São Paulo: Paulus, 2012.

FLUSSER, Vilém. Vampyroteuthis Infernalis: Eine Abhandlung samt Befund des Institut Scientifique de Recherche Paranaturaliste. Göttingen: European Photography, 2002.

Kommunikologie. Frankfurt am Main:

Fischer, 2007.

FREUD, Sigmund. Obas Psicológicas Completas

(Edição Standard: Volume XVII). Rio de Janeiro: Imago, 1976.

GRAY, Richard T. About Face: German Physiognomic Thought from Lavater to Auschwitz. Detroit: Wayne State University Press, 2004. 
GUMBRECHT, Hans Ulrich \& PFEIFFER, Ludwig (orgs.). Materialities of Communication. Stanford: Stanford University Press, 1994.

HAMES, Peter (ed.). The Cinema of Jan Svankmajer:

Dark Alchemy. London: Wallflower Press, 2008.

HANSSEN, Beatrice. Walter Benjamin's other History: of Stones, Animals, Human Beings , and Angels. Berkeley: University of California Press, 1998.

HARMAN, Graham. The Quadruple Object.

Winchester: Zero Books, 2011.

KAHN, Charles. The Art and Thought of Heraclitus (an edition of the fragments with translation and commentary). Cambridge: Cambridge University Press, 1979.

KIMMICH, Dorothee. Lebendige Dinge in der

Moderne. Konstanz: Konstanz University Press, 2011.

KRACAUER, Siegfried. Theory of Film: The

Redemption of Physical Reality. New York: Oxford University Press, 1960.

LATOUR, Bruno. Jamais fomos Modernos. Rio de Janeiro: editora 34, 2000.

LE B0T, Marc. Peinture et Machinisme. Paris:

Klincksieck, 1973.

LESLIE, Esther. Walter Benjamin: 0verpowering

Conformism. London: Pluto Press, 2000.

McCOLE, John. Walter Benjamin and the Antinomies of Tradition. Ithaca: Cornell University Press, 1993.

MENNINGHAUS, Winfried. Schwellenkunde: Walter

Benjamins Passage des Mythos. Frankfurt am Main: Suhrkamp, 1986.

\section{Walter Benjamins Theorie der}

Sprachmagie. Frankfurt am Main: Suhrkamp, 1995.

MILLER, Tyrus. 'Glass before its Time, Premature Iron': Architecture, Temporality and Dream in Benjamin's Arcades Project. In: HANSSEN, Beatrice (ed.). Walter
Benjamin and the Arcades Project. London:

Continuum, 2006.

MITRY, Jean. Historia del cine experimental.

Fernando Torres: Valencia, 1974.

M00RE, Rachel 0. Savage Theory: Cinema as

Modern Magic. Durham: Duke University Press, 2000.

NIETZSCHE, F. Werke in zwei Bände (Band I).

München: Carl Hanser, 1979.

NG, Julia. "Each Thing a Thief: Walter Benjamin on the Agency of Objects". Philosophy and Rhetoric, vol. 44, n. 4. Pennsylvania: Pennsylvania State University, 2011.

PANTENBURG, Volker (ed.). Cinematographic

Objects: Things and Operations. Berlin: August Verlag, 2015.

PAPAPETROS, Spyros. On the Animation of the Inorganic: Art, Architecture, and the Extension of Life. Chicago: University of Chicago Press, 2012.

PICARD, Max. Das Menschengesciht. ErlenbachZürich: Eugen Rentsch, 1947.

Die Welt des Schweigens. Fischer:

Frankfurt am Main, 1959 (1948).

PINEDA, Robin. The Essayistic Films of Olivier Smolders: Desire and Drive (Dissertação de Mestrado). Montreal: Concordia University, 2014. Disponível em < http://spectrum.library.concordia. ca/979004/1/Pineda_MA_F2014.pdf > . Acesso em 3 set. 2016

RAMPLEY, Matthew. The Remembrance of Things Past: on Aby Warburg and Walter Benjamin.

Wiesbaden: Harrassowitz, 2000.

SMOLDERS, Olivier. La part de l'ombre. Paris: Les Impressions Nouvelles, 2005.

STRAUSS, Marc Raymond. Hitchcock's Objects as Subjects: The Significance of Things on Screen. Jefferson: McFarland, 2016. 
TURVEY, Malcolm. Doubting Vision: Film and the

Revelationist Tradition. New York: Oxford University

Press, 2008.

WAA. 0s Pensadores Originários: Anaximandro,

Parmênides, Heráclito (trad. Emmanuel Carneiro

Leão e Sérgio Wrublewski). Petrópolis: Vozes, 1991. 


\begin{tabular}{|c|c|}
\hline $\begin{array}{l}\text { The Perfidy of Matter: Notes on } \\
\text { the Animation of the Inorganic }\end{array}$ & $\begin{array}{l}\text { La Perfidia de la Materia: notas } \\
\text { sobre la animación del inorgánico }\end{array}$ \\
\hline $\begin{array}{l}\text { Abstract } \\
\text { would it be possible to speak of a tradition that } \\
\text { expresses the "animation of the inorganic" in } \\
\text { experimental film and in the intercessions between } \\
\text { cinema and art? In other words, would there be, } \\
\text { in cinema's history, enough examples for the } \\
\text { vivification of inanimate objects (which sometimes } \\
\text { even become the focal point of the camera's gaze), } \\
\text { so that we could therein identify an expressive } \\
\text { aspect of modern aesthetics? Through some brief } \\
\text { analyses of cinematographic examples, but also of } \\
\text { elements from the fine arts and literature -, this } \\
\text { paper puts forward the hypothesis of a progressive } \\
\text { decline of the traditional anthropocentric point } \\
\text { of view and of the model of the liberal humanist } \\
\text { subjectivity from the turn of the XIX century on. } \\
\text { This decline will be exemplarily represented in } \\
\text { cinema and the arts through the ever more decisive } \\
\text { protagonism of objects. } \\
\text { Keywords } \\
\text { Objects. Experimental Cinema. Baroque. Walter } \\
\text { Benjamin. Jan Svankmajer }\end{array}$ & $\begin{array}{l}\text { Resumen } \\
\text { sería posible hablar de un tradición de la "animación } \\
\text { del inorgánico" en el cine experimental y en las } \\
\text { intercesiones entre cine y arte? En otras palabras, } \\
\text { existirían, en la historia del cine, ejemplos } \\
\text { suficientes de la vivificación de los objetos } \\
\text { inanimados (que por veces se vuelven el punto focal } \\
\text { de la mirada de la cámera), de modo que se pueda } \\
\text { identificar ahí un aspecto expresivo de la estética } \\
\text { moderna? Atraves de algunas breves análises } \\
\text { de ejemplos cinematográficos, pero también de } \\
\text { elementos del arte e de la literatura -, este trabajo } \\
\text { sugiere la hipótesis de un progresivo declínio del } \\
\text { punto de vista antropocéntrico e del modelo de la } \\
\text { subjetividad liberal humanista a partir de la virada } \\
\text { del siglo XIX. Ese declinio será ejemplarmente } \\
\text { representado en el cine y en las artes por medio del } \\
\text { protagonismo cada vez más decisivo de los objetos. } \\
\text { Palabras clave } \\
\text { Objectos. Cine experimental. Baroco. Walter } \\
\text { Benjamin. Jan Svankmajer }\end{array}$ \\
\hline
\end{tabular}




\section{Expediente}

A revista E-Compós é a publicação científica em formato eletrônico da Associação Nacional dos Programas de Pós-Graduação em Comunicação (Compós). Lançada em 2004, tem como principal finalidade difundir a produção acadêmica de pesquisadores da área de Comunicação, inseridos em instituições do Brasil e do exterior.

\section{E-COMPÓS I www.e-compos.org.br I E-ISSN 1808-2599}

Revista da Associação Nacional dos Programas de Pós-Graduação em Comunicação.

Brasília, v.19, n.3, set./dez. 2016.

A identificação das edições, a partir de 2008, passa a ser volume anual com três números.

Indexada por Latindex I www.latindex.unam.mx

\section{CONSELHO EDITORIAL}

Alexandre Farbiarz, Universidade Federal Fluminense, Brasil Alexandre Rocha da Silva, Universidade Federal do Rio Grande do Sul, Brasil Ana Carolina Escosteguy, Pontifícia Universidade Católica do Rio Grande do Sul, Brasil Ana Carolina Rocha Pessôa Temer, Universidade Federal de Goiás, Brasil Ana Regina Barros Rego Leal, Universidade Federal do Piauí, Brasil Andrea França, Pontifícia Universidade Católica do Rio de Janeiro, Brasil André Luiz Martins Lemos, Universidade Federal da Bahia, Brasil Antonio Carlos Hohlfeldt, Pontifícia Universidade Católica do Rio Grande do Sul, Brasil Arthur Ituassu, Pontifícia Universidade Católica do Rio de Janeiro, Brasil Álvaro Larangeira, Universidade Tuiuti do Paraná, Brasil Ângela Freire Prysthon, Universidade Federal de Pernambuco, Brasil César Geraldo Guimarães, Universidade Federal de Minas Gerais, Brasil Cláudio Novaes Pinto Coelho, Faculdade Cásper Líbero, Brasil Daisi Irmgard Vogel, Universidade Federal de Santa Catarina, Brasil Denize Correa Araujo, Universidade Tuiuti do Paraná, Brasil

Eduardo Antonio de Jesus, Pontifícia Universidade Católica de Minas Gerais, Brasil Daniela Zanetti, Universidade Federal do Espirito Santo, Brasil

Eduardo Vicente, Universidade de São Paulo, Brasil

Elizabeth Moraes Gonçalves, Universidade Metodista de São Paulo, Brasil Erick Felinto de Oliveira, Universidade do Estado do Rio de Janeiro, Brasil Francisco Elinaldo Teixeira, Universidade Estadual de Campinas, Brasil Francisco Paulo Jamil Almeida Marques, Universidade Federal do Paraná, Brasil Gabriela Reinaldo, Universidade Federal do Ceará, Brasil

Goiamérico Felício Carneiro Santos, Universidade Federal de Goiás, Brasil Gustavo Daudt Fischer, Universidade do Vale do Rio dos Sinos, Brasil Herom Vargas, Universidade Municipal de São Caetano do Sul, Brasil Itania Maria Mota Gomes, Universidade Federal da Bahia, Brasil Janice Caiafa, Universidade Federal do Rio de Janeiro, Brasil Jiani Adriana Bonin, Universidade do Vale do Rio dos Sinos, Brasil
José Afonso da Silva Junior, Universidade Federal de Pernambuco, Brasil José Luiz Aidar Prado, Pontifícia Universidade Católica de São Paulo, Brasil Juçara Gorski Brittes, Universidade Federal de Ouro Preto, Brasil Kati Caetano, Universidade Tuiuti do Paraná, Brasil Lilian Cristina Monteiro França, Universidade Federal de Sergipe, Brasil Liziane Soares Guazina, Universidade de Brasilia, Brasil Luíza Mônica Assis da Silva, Universidade de Caxias do Sul, Brasil Luciana Miranda Costa, Universidade Federal do Pará, Brasil Malena Segura Contrera, Universidade Paulista, Brasil Monica Martinez, Universidade de Sorocaba, Brasi Maria Ataide Malcher, Universidade Federal do Pará, Brasil Marcia Tondato, Escola Superior de Propaganda e Marketing, Brasil Marcel Vieira Barreto Silva, Universidade Federal da Paraíba, Brasil Maria Clotilde Perez Rodrigues, Universidade de São Paulo, Brasil Maria das Graças Pinto Coelho, Universidade Federal do Rio Grande do Norte, Brasil Mauricio Ribeiro da Silva, Universidade Paulista, Brasil

Mauro de Souza Ventura, Universidade Estadual Paulista, Brasil Márcio Souza Gonçalves, Universidade do Estado do Rio de Janeiro, Brasil Micael Maiolino Herschmann, Universidade Federal do Rio de Janeiro, Brasil Mirna Feitoza Pereira, Universidade Federal do Amazonas, Brasil Nísia Martins Rosario, Universidade Federal do Rio Grande do Sul, Brasil Potiguara Mendes Silveira Jr, Universidade Federal de Juiz de Fora, Brasil Regiane Regina Ribeiro, Universidade Federal do Paraná, Brasil Rogério Ferraraz, Universidade Anhembi Morumbi, Brasil Rose Melo Rocha, Escola Superior de Propaganda e Marketing, Brasil Rozinaldo Antonio Miani, Universidade Estadual de Londrina, Brasil Sérgio Luiz Gadini, Universidade Estadual de Ponta Grossa, Brasil Simone Maria Andrade Pereira de Sá, Universidade Federal Fluminense, Brasil Veneza Mayora Ronsini, Universidade Federal de Santa Maria, Brasil Walmir Albuquerque Barbosa, Universidade Federal do Amazonas, Brasil

\section{CONSELHO CIENTÍFICO}

Cristiane Freitas Guttreind, Pontifícia Universidade Católica do Rio Grande do Sul, Brasil Eduardo Morettin, Universidade de São Paulo, Brasil Felipe Costa Trotta, Universidade Federal Fluminense, Brasil Irene de Araújo Machado, Universidade de São Paulo, Brasil

\section{COMISSÃO EDITORIAL}

Eduardo Antonio de Jesus, Pontifícia Universidade Católica de Minas Gerais, Brasil Osmar Gonçalves dos Reis Filho, Universidade Federal do Ceará, Brasil

\section{CONSULTORES AD HOC}

Geane C. Alzamora, Universidade Federal de Minas Gerais, Brasil Teresinha Cruz Pires, Pontifícia Universidade Católica de Minas Gerais, Brasil

\section{EQUIPE TÉCNICA}

ASSISTENTE EDITORIAL Márcio Zanetti Negrini

REVISÃO DE TEXTOS Press Revisão

EDITORAÇÃO ELETRÔNICA Roka Estúdio

IMAGEM DE CAPA Silas de Paula

\section{COMPÓS I www.compos.org.br}

Associação Nacional dos Programas de Pós-Graduação em Comunicação

Presidente

Edson Fernando Dalmonte

Programa de Pós-Graduação em Comunicação

e Cultura Contemporânea - UFBA

edsondalmonte@uol.com.br

Vice-presidente

Cristiane Freitas Gutfreind

Programa de Pós-Graduação em Comunicação Social - PUC-RS cristianefreitas@pucrs.br

Secretário-Geral

Rogério Ferraraz

Programa de Pós-Graduação em Comunicação

Universidade Anhembi Morumbi

rogerioferraraz@anhembimorumbi.edu.br

CONTATO I revistaecompos@gmail.com 